\title{
Well-designed $\mathrm{CdS} / \mathrm{TiO}_{2} / \mathrm{MS}^{-\mathrm{SiO}_{2}} \mathrm{Z}$-scheme photocatalyst for combating poison with poison
}

Jie Wang, Sijia Sun, Hao Ding *, Wei Li, Xuan Wang

Beijing Key Laboratory of Materials Utilization of Nonmetallic Minerals and Solid Wastes, National Laboratory of Mineral Materials, School of Materials Science and Technology, China University of Geosciences, Beijing 100083, China

Beijing Building Materials Academy Of Sciences Research Co.,Ltd., Beijing, 100041, China 


\section{Experimental details}

\section{Characterizations}

The crystal structure of the samples is characterized by powder X-ray diffraction (XRD) analysis on a D8-ADVANCE X-ray power diffractometer (Bruker,Germany) with $\mathrm{Cu} \mathrm{K} \alpha$ radiation $(\lambda=0.15406 \mathrm{~nm})$ under the operation conditions of $40 \mathrm{kV}$ and 40 $\mathrm{mA}$. The samples are scanned in the range of $2 \theta$ from $10^{\circ}$ to $80^{\circ}$ with a $0.02^{\circ}$ step at a scanning speed of $4 \% \mathrm{~min}$. We observe the morphology of different samples by scanning electron microscope (SEM) (S-3500N, Japan) and transmission electron microscope (TEM) (FEI Tecnai G2 F20, Portland). X-ray photoelectron spectroscopy (XPS) data are collected on Thermo ESCALAB250 instrument with a monochromatized Al Ka line source $(200 \mathrm{~W})$. The UV-vis diffuse reflectance spectrum are tested with a spectrophotometer (Cary 5000, Varian). Besides, the free radicals generated from different samples are tested by electron paramagnetic resonance (EPR) (Bruker A300,Germany). When DMPO was selected as free radical capture agent, $\cdot \mathrm{OH}$ is measured in water. The photoluminescence (PL) spectra is measured on a high-resolution multi-function imaging spectrometer (iHR 550) using laser transmitter $(532 \mathrm{~nm})$. Zeta potential is measured on Zeta potentiometer (DT-300, America). The electrochemical impedance spectroscopy (EIS) and photocurrent of as-prepared photocatalyst are measured by an electrochemical analyzer (CHI-660B, China). The measurements of electrochemical impedance spectroscopy (EIS) and photocurrent are processed under a standard three-electrode system using the prepared samples as the working electrodes, a Pt wire as the counter electrode, and aturated 
calomel electrod as a reference electrode. A $300 \mathrm{~W}$ Xe lamp served as the light source. The working electrodes are prepared as follows. $10 \mathrm{mg}$ of sample are dispersed in $1 \mathrm{ml}$ ethanol solution and ultrasonicated to form uniform suspension. Next, the suspension is dropped on to the ITO glass and dried in air. Then, the prepared electrode is heated at $120^{\circ} \mathrm{C}$ for $4 \mathrm{~h}$.

\section{Evaluation of Photocatalytic property}

The photocatalytic degradation performance of photocatalyst is tested with the Rhodamine $\mathrm{B}$ and $\mathrm{Cr}(\mathrm{VI})$ as the target degradation pollutant. The suspension was first stirred in the dark for $60 \mathrm{~min}$ to reach an adsorption/desorption equilibrium between catalysts and solution. At a specific interval, $5 \mathrm{~mL}$ of suspension is sampled, separated through centrifugation at $10000 \mathrm{rpm}$. Then the concentrations of $\mathrm{RhB}$ was measured by a UV-Vis spectrophotometer with the absorbance of the solution at $554 \mathrm{~nm}$. The concentration of $\mathrm{Cr}$ (VI) was determined by diphenyl carbazide method (DPC). After mixing $0.2 \mathrm{~g}$ 1,5-diphenyl carbazide with $50 \mathrm{~mL}$ acetone and $50 \mathrm{~mL}$ distilled water for color development and then put into a brown bottle. Then above chromogenic solution was added in determinand, which was placed for $5 \mathrm{~min}$. The absorbance was measured by a UV-Vis spectrophotometer with the absorbance of the solution at 540 $\mathrm{nm}$.

The photocatalytic degradation performance of the samples is characterized and evaluated based on the change of concentration $\left(\mathrm{C} / \mathrm{C}_{0}, \mathrm{C}_{0}\right.$ is the initial concentration, $\mathrm{C}$ is the concentration at irradiation time $\mathrm{t}$ ). Due to the reactant concentration is low, thus the degradation process is according with the following pseudo first-order 
kinetics equation (Formula.1). $\mathrm{K}_{\mathrm{app}}$ is the pseudo-first-order rate constant $\left(\mathrm{min}^{-1}\right)$.

$$
\ln \frac{c}{c_{0}}=-k_{a p p} t
$$

\section{Photoelectrochemical measurement}

The electrochemical and photoelectrochemical (PEC) properties of the samples, such as the measurement of transient photocurrent, AC impedance, and Mott-Schottky curves are measured at the $\mathrm{CHI} 660 \mathrm{~B}$ electrochemical workstation. Using a standard three-electrode quartz cells with $0.1 \mathrm{~mol} / \mathrm{L}$ of $\mathrm{Na}_{2} \mathrm{SO}_{4}$ as the electrolyte, the calomel electrode is the reference electrode, Pt is the counter electrode, and the ITO glass coated with the sample is the working electrode. A $300 \mathrm{~W}$ xenon lamp is used as the light source for PEC measurements.

Preparation of the sample electrodes: First, the ITO glass pieces need to be pretreated. The side with resistance is measured by the universal meter and placed in the detergent solution and deionized water respectively to produce a cleaning for $0.5 \mathrm{~h}$. Then the ITO glass pieces are boiled for 30 minutes in a solution concluding ammonia water, $\mathrm{H}_{2} \mathrm{O}_{2}$ and $\mathrm{H}_{2} \mathrm{O}$ in a certain molar ratio. After that, they are washed with ethanol for 2-3 times and blown dry with a hair dryer. With the resistance side upward, these ITO glass pieces are irradiated for 1 hour by the ultraviolet lamp. $10 \mathrm{mg}$ sample powder is dispersed in $1 \mathrm{ml}$ of ethanol and sonicated for about 15 minutes. Then the sample is dropped onto a flat glass piece with a dropper, and after being air-dried (about $12 \mathrm{~h}$ ), it was placed in an oven and heated.

\section{Measurement of photocatalytic water splitting}

The photolysis water hydrogen production device is a Lab solar photolysis water hydrogen production system produced by Beijing Perfectlight Technology Co, Ltd. The system mainly includes gas chromatography analysis, circulation pipeline, reaction vessel and vacuum pump. In the experiment, $100 \mathrm{mg}$ of catalyst, $90 \mathrm{ml}$ of deionized water and $10 \mathrm{ml}$ of methanol (used as a hole trapping agent) are placed in a quartz reactor with a quartz lid covered. A $300 \mathrm{w}$ xenon lamp is used as the light 
source for photocatalytic reaction. The product hydrogen is detected by gas chromatography (GC-2014, Shimadzu Corp, Japan).

\subsection{Photoelectric properties and mechanism}

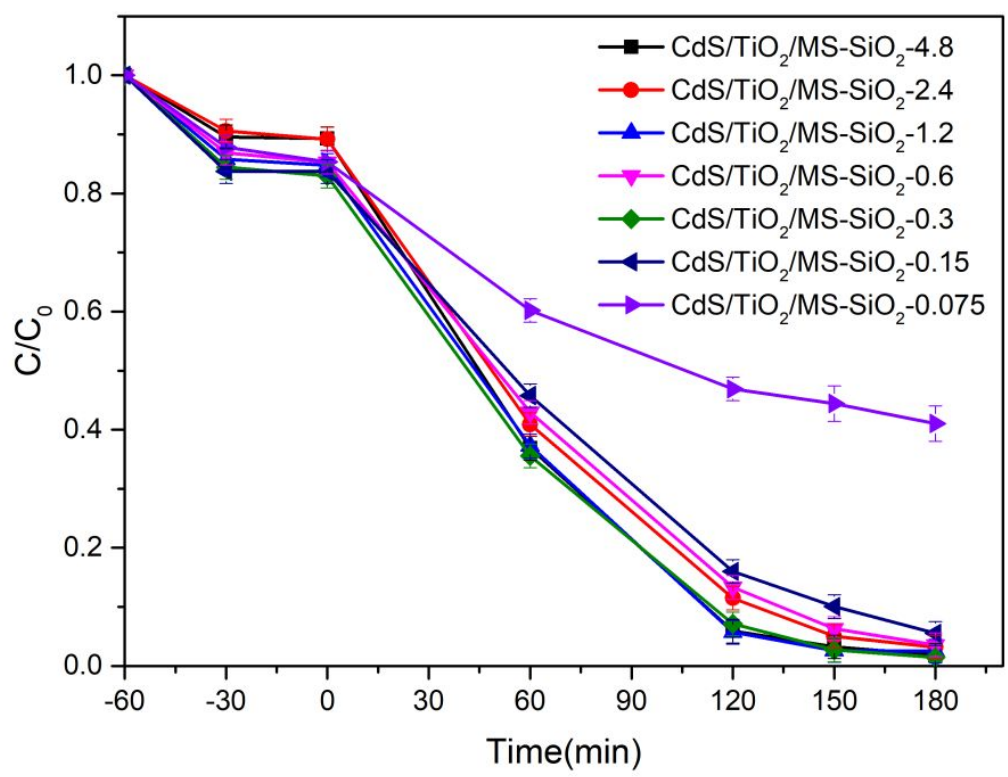

Figure S1. Removal rate of RhB for different samples.

$\left(\mathrm{CdS} / \mathrm{TiO}_{2} / \mathrm{MS}^{-\mathrm{SiO}_{2}}-\mathrm{X}, \mathrm{X}\right.$ is the mass multiple of $\mathrm{CdS}$ to $\left.\mathrm{TiO}_{2} / \mathrm{MS}_{-} \mathrm{SiO}_{2}\right)$.

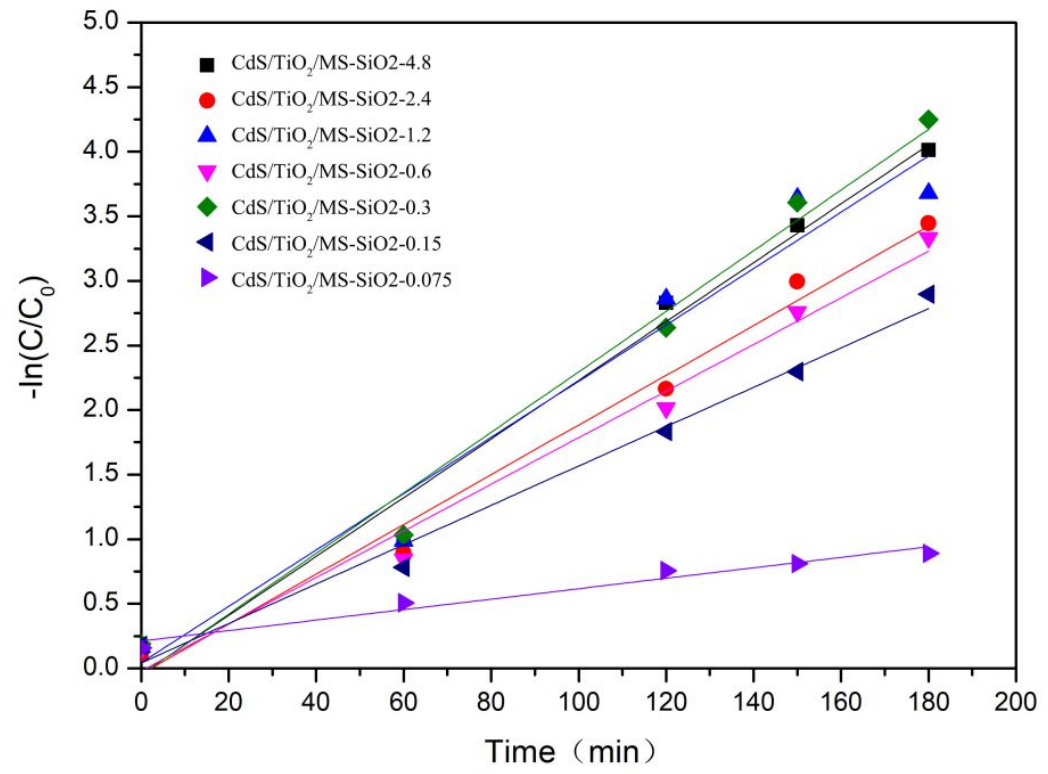

Figure S2. Photocatalytic degradation kinetics parameters of RhB for different samples $\left(\mathrm{CdS} / \mathrm{TiO}_{2} / \mathrm{MS}-S i O_{2}-\mathrm{X}, \mathrm{X}\right.$ is the mass multiple of $\mathrm{CdS}$ to $\left.\mathrm{TiO}_{2} / \mathrm{MS}-\mathrm{SiO}_{2}\right)$. 


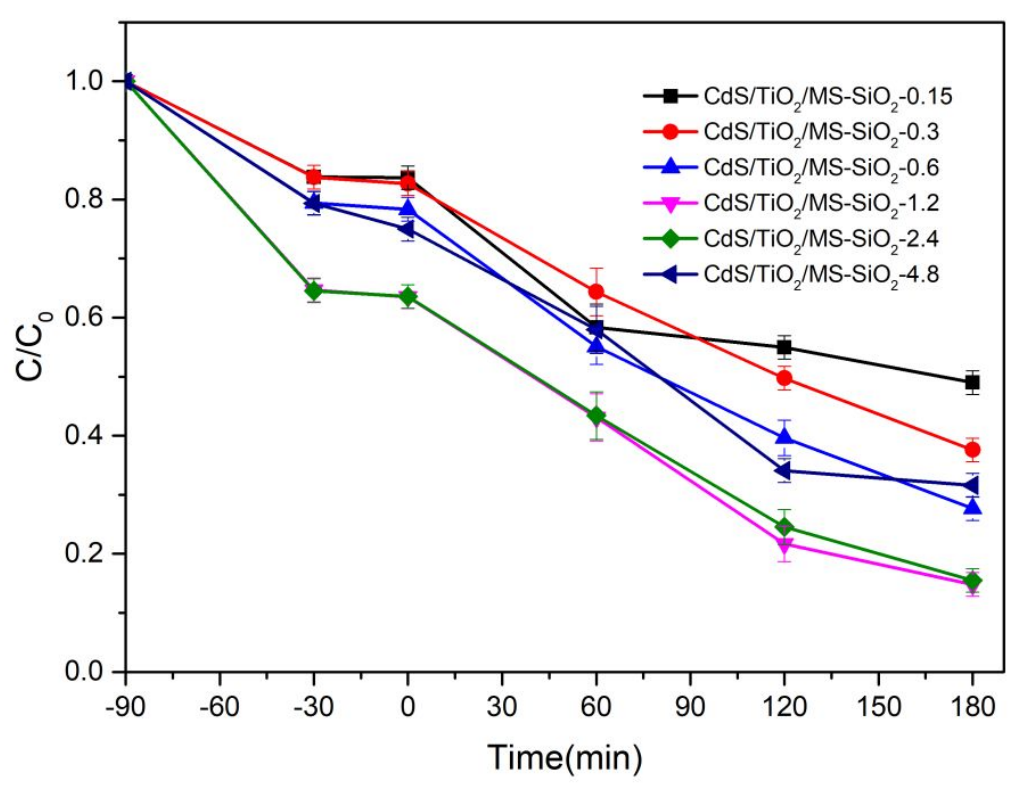

Figure S3. Removal rate of $\mathrm{Cr}(\mathrm{VI})$ for different samples.

$\left(\mathrm{CdS} / \mathrm{TiO}_{2} / \mathrm{MS} \mathrm{SiO}_{2}-\mathrm{X}, \mathrm{X}\right.$ is the mass multiple of $\mathrm{CdS}$ to $\left.\mathrm{TiO}_{2} / \mathrm{MS}-\mathrm{SiO}_{2}\right)$.

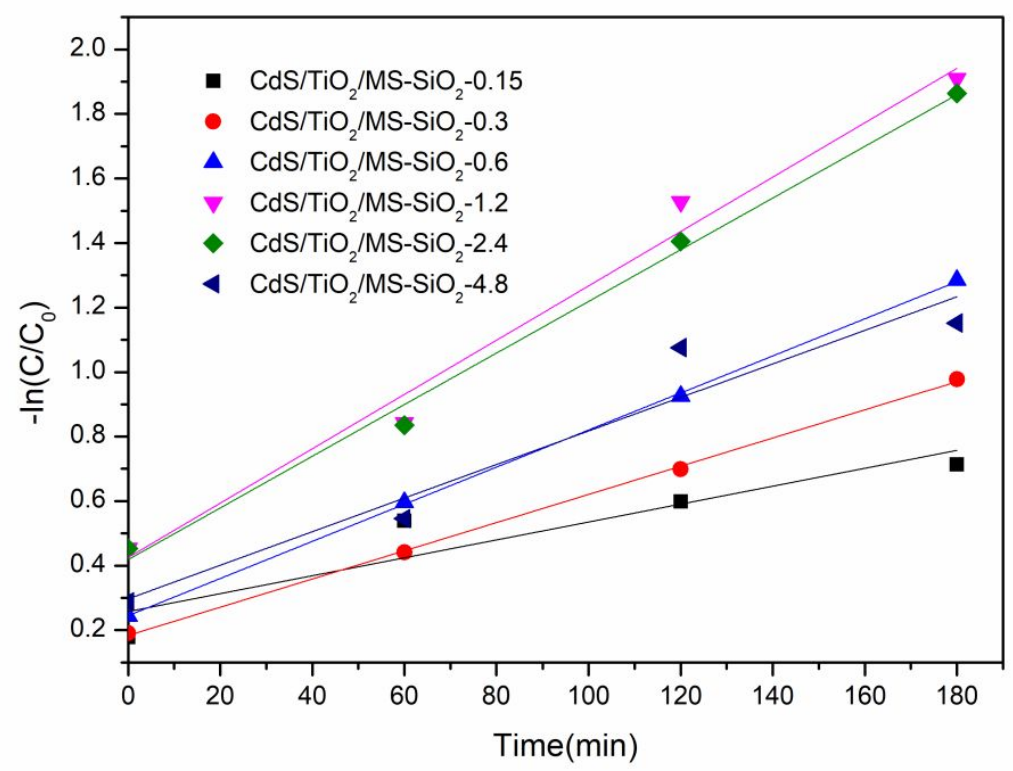

Figure S4. Photocatalytic degradation kinetics parameters of Cr(VI) for different samples.

$\left(\mathrm{CdS} / \mathrm{TiO}_{2} / \mathrm{MS}^{-S_{i O}}{ }_{2}-\mathrm{X}, \mathrm{X}\right.$ is the mass multiple of $\mathrm{CdS}$ to $\left.\mathrm{TiO}_{2} / \mathrm{MS}^{-\mathrm{SiO}_{2}}\right)$. 


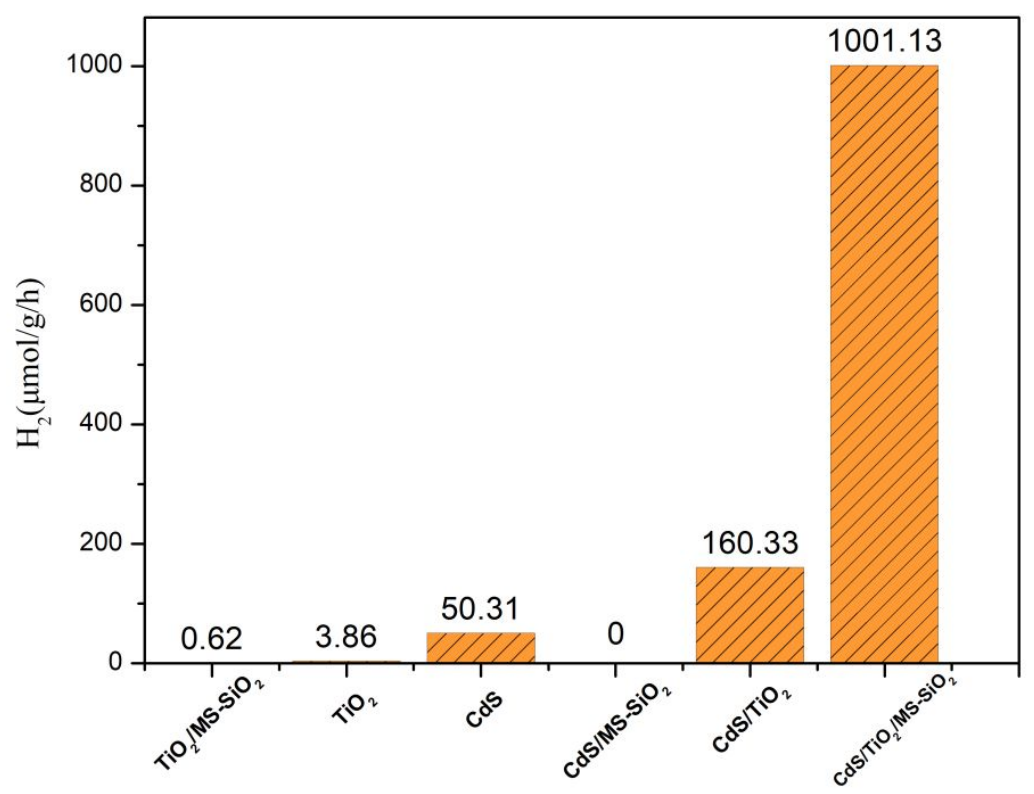

Figure S5. The $\mathrm{H}_{2}$ generation rates of different samples. 